\title{
Deep Anterior Lamellar Keratoplasty Following Epikeratophakia: A Novel Two-Stage One-Graft Method To Treat Acute Corneal Hydrops
}

\section{Chunyu Liu}

Tongji University School of Medicine

\section{Xinyu Huang}

Tongji University School of Medicine

\section{Xin Liu}

Tongji University School of Medicine

\author{
Yushan Zhang \\ Tongji University School of Medicine
}

\section{Jiaqi Shen}

Tongji University School of Medicine

Li Zhang ( $\square$ trudyzhang@163.com )

Tongji University School of Medicine

Yanlong Bi

Tongji University School of Medicine

\section{Research Article}

Keywords: Acute corneal hydrops, Epikeratophakia, Deep anterior lamellar keratoplasty, Anterior segment optical coherence tomography, Descemet's membrane

Posted Date: November 10th, 2021

DOl: https://doi.org/10.21203/rs.3.rs-1028848/v1

License: (-) (1) This work is licensed under a Creative Commons Attribution 4.0 International License. Read Full License 


\section{Abstract \\ Purpose}

To evaluate the clinical effects of deep anterior lamellar keratoplasty (DALK) using a single graft after epikeratophakia for the treatment of acute corneal hydrops.

\section{Methods}

This novel surgical procedure was performed on seven eyes of seven patients between 2019 and 2020. The procedure combines a first-stage surgery of epikeratophakia with intracameral sterile air injection and a second-stage surgery of DALK using the same corneal graft for both procedures. Main outcome measures included pre- and postoperative bestcorrected visual acuity (BCVA) and anterior segment optical coherence tomography (AS-OCT) parameters. Corneal transparency, neovascularization and epithelization were observed at the 1-year follow-up.

\section{Results}

Corneal edema resolved rapidly in six of the seven cases. The group mean central corneal thickness was significantly reduced from baseline at 1 day, 1 week, 1 month, and 2 months after the first-stage surgery, respectively $(P<0.0001)$. At a mean of $2.1 \pm 0.7$ months after the first-stage surgery, DALK was successfully performed in all cases. Six months later, the central corneal thickness was $611 \pm 31 \mu \mathrm{m}$ and the thickness of the recipient's residual stroma bed was $20 \pm 6 \mu \mathrm{m}$ at the central corneal area. LogMAR BCVA was improved from $1.74 \pm 0.34$ at baseline to $0.20 \pm 0.11$ after DALK $(P<0.0001)$. No postoperative complications appeared in our case series during one years of observation.

\section{Conclusion}

A novel curative effect was found in the treatment of acute corneal hydrops with epikeratophakia followed by DALK using the same corneal graft.

\section{Key Messages}

Keratoconus is a chronic ectatic corneal disorder. Once keratoconus progresses to the acute stage, it may bring severe complications such as acute corneal hydrops $(\mathrm{ACH})$, which may result in corneal scars and vision loss. Deep anterior lamellar keratoplasty is now the preferred method to treat deep corneal stromal lesions. However, when ACH arises in keratoconus, disruption of Descemet's membrane (DM) and the endothelium may create difficulties in performing a complete DALK. In this study, we designed a novel and safe two-stage surgical procedure. The first stage involves epikeratophakia combined with intracameral air injection to accelerate the $\mathrm{ACH}$ healing and the second stage is the DALK procedure using the same graft.

\section{Introduction}

Keratoconus is a chronic ectatic corneal disorder characterized by irregular astigmatism and myopia caused by corneal thinning and extension. Once keratoconus progresses to the acute stage, it may bring severe complications such as acute corneal hydrops (ACH), which may result in corneal scars and vision loss. ${ }^{1,2}$ Although $\mathrm{ACH}$ is usually self-limiting and generally resolves without intervention over 2-4 months, ${ }^{3}$ longer duration of $\mathrm{ACH}$ is more likely to lead to 
complications such as neovascularization, ${ }^{4}$ pseudocyst formation, ${ }^{5}$ infection, malignant glaucoma, and corneal perforation. ${ }^{6,7}$ Left untreated, patients are at a high risk of exacerbating endothelial cell loss. ${ }^{8} \mathrm{~A}$ history of $\mathrm{ACH}$ may also increase the risk of endothelial graft rejection after penetrating keratoplasty. ${ }^{9}$ Deep anterior lamellar keratoplasty (DALK) is now the preferred method to treat deep corneal stromal lesions. During DALK, the healthy endothelium of the recipient cornea can be preserved, avoiding postoperative endothelial immune rejection ${ }^{10}$ and chronic endothelial dysfunction. ${ }^{11}$ The graft is cell-extracted and preserved by freezing in glycerol, so the risk of stromal immune rejection is also low after DALK. ${ }^{12}$ However, when ACH arises in keratoconus, disruption of Descemet's membrane (DM) and the endothelium may create difficulties in performing a complete DALK. ${ }^{1,9}$ In this study, we designed a novel and safe two-stage surgical procedure. The first stage involves epikeratophakia combined with intracameral air injection to accelerate the $\mathrm{ACH}$ healing and the second stage is the DALK procedure using the same graft.

\section{Materials And Methods}

\section{Ethics Statement}

This retrospective, interventional, nonrandomized observational study was approved by the ethics committee of the Shanghai Tongji Hospital of Tongji University. After a thorough explanation about the nature of the study, all patients agreed to participate and provided written informed consents to participate prior to study entry. Signed consent was obtained from patients for all clinical photographs that permit their identification and is archived by the authors. Furthermore, this study conformed to the ethical standards outlined in the Declaration of Helsinki.

\section{Patients}

In this study, the novel procedure was performed on seven eyes of seven patients between February 2019 and May 2021 at the department of ophthalmology affiliated with the Tongji University School of Medicine. The patients were aged between 17 and 21 years (mean 18.9 \pm 1.4 years), and all were diagnosed with $\mathrm{ACH}$ immediately after onset of symptoms. Among the cases, the mean ACH duration was $25.9 \pm 6.1$ days. None of the patients had previously undergone corneal surgery or been treated with rigid gas permeable (RGP) contact lenses. All patients underwent relevant ophthalmic examinations pre and postoperatively, including slit-lamp examination and best corrected visual acuity (BCVA). The extent of corneal edema, corneal thickness, the location and size of the DM breaches were evaluated by anterior segment optical coherence tomography (AS-OCT) examination.

\section{Surgical procedure}

All surgeries were performed by the same surgeon ( $\mathrm{YL} \mathrm{Bi}$ ). The first-stage surgery was epikeratophakia combined with injection of sterile air into the anterior chamber. The recipient bed was prepared first, followed by cauterization of the edematous cornea using bipolar electrocautery forceps. During this procedure, the epithelium of the pathological cornea was cauterized and stripped, and the subepithelial tissue was also cauterized until the pathological cornea was visibly flatter. At this step, the heat of the cauterization was controlled within the appropriate range to minimize corneal stromal scarring and damage to the corneal endothelium. The corneal cone taper position was determined by slit lamp microscopy before surgery (the mean cone bottom diameter of this group of cases was $8.51 \pm 0.26 \mathrm{~mm}$ ). A partial thickness trephination was then made to a depth of about $200 \mu \mathrm{m}$ with a vacuum trephine of corresponding dimension, and a peripheral pocket was created for insertion of the wing of the donor graft. The prepared donor graft was a decellularized homograft which had been stored at $-78^{\circ} \mathrm{C}$ in pure sterile glycerin, and $1.5 \mathrm{~mm}$ larger than the previous trephine (the average of this group of cases is $10.07 \pm 0.32 \mathrm{~mm}$ ) was then sutured in place with interrupted 10-0 nylon. A paracentesis of the anterior chamber was applied at the 9 o'clock position to decrease the intraocular pressure, and $1 \mathrm{ml}$ sterile air was then injected into the anterior chamber to compress the break in the pathological DM (Fig. 1A, 1B). The 
eye under treatment was covered with a bandage contact lens and a compression bandage. The patient was instructed to rest in the supine position as much as possible after surgery, avoiding strenuous exercise and eye rubbing.

The second-stage surgery was DALK. About 2 months after the epikeratophakia (in this case series, the mean period was $2.1 \pm 0.7$ months), DALK was performed using the same corneal graft. The edge of the peripheral stromal pocket and the edge of the donor graft were identified and the donor graft was then completely dissociated and temporarily preserved in an empty moist chamber. After initial trephination, the incisal edge was held using fine toothed forceps and was dissected at about 4/5 thickness. During this process, the manual dissections were performed carefully three to five times in most cases to avoid further damaging the DM. When the anterior stroma was dissected (at approximately 50\% thickness), a sterile air bubble was injected into the anterior chamber to avoid rapid aqueous leakage from the reopening of the healed DM breaks and its further edema. If modest leakage was observed from the stromal bed, the manual dissection was conducted more carefully and quickly. In all of our cases, the same donor grafts were used in the second-stage DALK. The graft was reversed, placed, and trimmed on the cutting-off table using a trephine $0.5 \mathrm{~mm}$ larger than the recipient bed. During this procedure the corneal epithelium was carefully protected. The donor graft was then fixed using 10-0 interrupted nylon sutures. (Fig. 1C)

\section{AS-OCT examination}

The corneal morphologic examination was performed using AS-OCT (Carl Zeiss Meditec, USA). Preoperative measurements included the thickness of the corneal apex $\left(T_{a}\right)$, the corneal thickness $2 \mathrm{~mm}$ nasal and temporal to the corneal apex, as determined by horizontal $\left(T_{n h}, T_{\text {th }}\right)$ and vertical $\left(T_{n v}, T_{t v}\right)$ scans (Fig. 2). If the DM was detached, the width of the DM detachment was measured using different scan directions, and the maximum distance from the detached membrane to the posterior corneal surface was also determined. The above measurements and the thickness of the central recipient bed (Tr) were measured at 1 day, 1 week, 1 month, and 2 months after the first-stage surgery and again at 6 months after the second-stage surgery.

\section{Statistical analysis}

Data were analyzed statistically using SPSS Version 21.0 (SPSS Inc., IBM, USA), and the results were expressed as mean \pm standard deviation. A paired samples t-test was used to test the preoperative and postoperative $T_{a}, T_{n h}, T_{t h}, T_{n v}$, and $T_{\text {tv }}$ values, with $P<0.05$ considered statistically significant.

\section{Results}

All seven surgeries were performed successfully without intraoperative or postoperative complications. After the first stage surgery, the DM was reattached to the posterior corneal stroma in all patients. In six patients, the corneal edema subsided rapidly 1 day after surgery and gradually decreased over the next 2 weeks (Table 1). Edema in one case took 5 days to resolve due to a large break in the DM (Fig. 2). One patient, who had been treated with thermokeratoplasty for emergency management upon diagnosis of $\mathrm{ACH}$ had a recurrence of edema 2 weeks after surgery and had to undergo epikeratophakia to release the corneal hydrops (Fig. 3). 
Table 1

AS-OCT results preoperatively and 2 months after the first-stage surgery

\begin{tabular}{|c|c|c|c|c|c|}
\hline & Pre-operation & 1 day & 1 week & 1 month & 2 months \\
\hline $\mathrm{T}_{\mathrm{a}}(\mu \mathrm{m})$ & $1870 \pm 243$ & $1373 \pm 221^{*}$ & $1186 \pm 129^{*}$ & $1157 \pm 131^{*}$ & $1063 \pm 125^{*}$ \\
\hline$T_{r}(\mu m)$ & / & $778 \pm 120$ & $603 \pm 72^{\#}$ & $567 \pm 21^{\#}$ & $520 \pm 10^{\#}$ \\
\hline $\mathrm{T}_{\mathrm{nh}}(\mu \mathrm{m})$ & $1368 \pm 244$ & $1284 \pm 216^{*}$ & $1153 \pm 154^{*}$ & $1124 \pm 142^{*}$ & $1042 \pm 97^{*}$ \\
\hline $\mathrm{T}_{\mathrm{th}}(\mu \mathrm{m})$ & $1412 \pm 263$ & $1307 \pm 239^{*}$ & $1172 \pm 150^{*}$ & $1136 \pm 145^{\star}$ & $1050 \pm 101^{*}$ \\
\hline $\mathrm{T}_{\mathrm{nv}}(\mu \mathrm{m})$ & $1344 \pm 269$ & $1221 \pm 218^{*}$ & $1130 \pm 180^{*}$ & $1104 \pm 171^{*}$ & $1033 \pm 138^{*}$ \\
\hline $\mathrm{T}_{\mathrm{tv}}(\mu \mathrm{m})$ & $1238 \pm 258$ & $1189 \pm 238^{*}$ & $1118 \pm 200^{*}$ & $1080 \pm 173^{*}$ & $1021 \pm 129^{*}$ \\
\hline \multicolumn{6}{|c|}{$\begin{array}{l}\text { Ta: corneal apex thickness; Tr: central recipient bed thickness; Tnh: corneal thickness } 2 \mathrm{~mm} \text { nasal to the corneal } \\
\text { apex, determined with a horizontal scan; Tth: corneal thickness } 2 \mathrm{~mm} \text { temporal to the corneal apex, determined with } \\
\text { a horizontal scan; Tnv: corneal thickness } 2 \mathrm{~mm} \text { nasal to the corneal apex, determined with a vertical scan; Ttv: } \\
\text { corneal thickness } 2 \mathrm{~mm} \text { temporal to the corneal apex, determined with a vertical scan. } * P \text { value }<0.05 \text { compared } \\
\text { with the preoperative values; } \# P \text { value }<0.05 \text { compared with the values measured } 1 \text { day after surgery. }\end{array}$} \\
\hline
\end{tabular}

Before the second-stage surgery, all breaks in the DM were almost healed and the corneal stroma was in a nonedematous condition, based on the corneal morphologic parameters measured using AS-OCT. During the second stage DALK, the pre-DM corneal stroma was exposed as much as possible. In two cases, slow aqueous leakage was observed in the deep corneal stroma when the manual dissection was performed close to the DM. In addition, mild effusion between graft and bed was observed in one patient 1 day after DALK. After topical anesthesia, a lacrimal irrigating needle was used to gently open the wound between the two sutures at 5 o'clock. The wound was pressed down gently, the interlaminar fluid could be seen flowing out, the double anterior sign disappeared immediately, and the corneal edema decreased gradually within 5 days without recurrence.

At 6 months after DALK, the BCVA was restored to $0.20 \pm 0.11$ in this group of cases, and the graft-recipient bed was well attached on observation of AS-OCT images (Fig. 4). The central and paracentral corneal thickness were significantly reduced compared with pre-operative measures, and the thickness of central residual corneal stroma was $20 \pm 6 \mu \mathrm{m}$ (Table 2). 
Table 2

AS-OCT results preoperatively and 6 months after the second-stage surgery

\begin{tabular}{|c|c|c|c|c|c|c|c|c|c|c|}
\hline Case & Sex & Age & Eye & $\begin{array}{l}\text { logMAR } \\
\text { BCVA } \\
\text { Pre/Post }\end{array}$ & $\begin{array}{l}\mathrm{T}_{\mathrm{a}}(\mu \mathrm{m}) \\
\text { Pre/Post }\end{array}$ & $\begin{array}{l}\mathrm{T}_{\mathrm{nh}}(\mu \mathrm{m}) \\
\text { Pre/Post }\end{array}$ & $\begin{array}{l}\mathrm{T}_{\text {th }}(\mu \mathrm{m}) \\
\text { Pre/Post }\end{array}$ & $\begin{array}{l}\mathrm{T}_{\mathrm{nv}}(\mu \mathrm{m}) \\
\text { Pre/Post }\end{array}$ & $\begin{array}{l}T_{\mathrm{tv}}(\mu \mathrm{m}) \\
\text { Pre/Post }\end{array}$ & $\begin{array}{l}T_{r} \\
(\mu \mathrm{m})\end{array}$ \\
\hline 1 & $M$ & 18 & right & $1.52 / 0.22$ & $1770 / 631$ & $1230 / 672$ & $1663 / 660$ & $1023 / 662$ & $1120 / 657$ & 15 \\
\hline 2 & $\mathrm{~F}$ & 19 & left & $2.30 / 0.40$ & $2271 / 654$ & $1543 / 702$ & $1346 / 698$ & $1106 / 685$ & $923 / 674$ & 25 \\
\hline 3 & $M$ & 21 & right & $1.52 / 0.13$ & $1880 / 608$ & $1787 / 648$ & $1530 / 631$ & $1700 / 629$ & $1305 / 641$ & 28 \\
\hline 4 & $M$ & 18 & left & $1.70 / 0.10$ & $2082 / 566$ & $1503 / 585$ & $1556 / 578$ & $1606 / 581$ & $1692 / 572$ & 24 \\
\hline 5 & $\mathrm{M}$ & 17 & left & $1.85 / 0.28$ & $1621 / 594$ & $1302 / 624$ & $1140 / 632$ & $1550 / 612$ & $1321 / 631$ & 21 \\
\hline 6 & $\mathrm{~F}$ & 19 & left & $1.30 / 0.22$ & $1592 / 587$ & $1040 / 602$ & $992 / 610$ & $1201 / 620$ & $985 / 633$ & 11 \\
\hline 7 & $\mathrm{M}$ & 20 & right & $2.00 / 0.09$ & $1874 / 636$ & $1298 / 700$ & $1660 / 698$ & $1222 / 673$ & $1320 / 667$ & 18 \\
\hline \multirow[t]{2}{*}{$\begin{array}{l}\text { Mean } \\
\pm S D\end{array}$} & & & & $\begin{array}{l}1.74 \pm \\
0.34 /\end{array}$ & $\begin{array}{l}1870 \pm \\
243 /\end{array}$ & $\begin{array}{l}1368 \pm \\
244 /\end{array}$ & $\begin{array}{l}1412 \pm \\
263 /\end{array}$ & $\begin{array}{l}1344 \pm \\
269 /\end{array}$ & $\begin{array}{l}1238 \pm \\
258 /\end{array}$ & $\begin{array}{l}20 \pm \\
6\end{array}$ \\
\hline & & & & $\begin{array}{l}0.20 \pm \\
0.11\end{array}$ & $611 \pm 31$ & $648 \pm 46$ & $644 \pm 45$ & $637 \pm 37$ & $639 \pm 34$ & \\
\hline $\begin{array}{l}t \\
\text { value }\end{array}$ & & & & 13.227 & 14.258 & 8.097 & 8.026 & 6.294 & 5.548 & \\
\hline $\begin{array}{l}P \\
\text { value }\end{array}$ & & & & $<0.0001$ & $<0.0001$ & $<0.0001$ & $<0.0001$ & 0.001 & 0.001 & \\
\hline
\end{tabular}

\section{Discussion}

$\mathrm{ACH}$ is a severe complication caused by disruption and local detachment of the DM, secondary to increasing corneal ectasia in conditions such as keratoconus. ${ }^{13,14}$ Due to its elasticity, DM retracts or coils when it breaks under tension. The aqueous humor flows into the corneal stroma, causing severe corneal edema and opacity. ${ }^{14,15}$ The conventional therapies for $\mathrm{ACH}$ consist of non-surgical treatments, such as wearing rigid gas-permeable contact lenses (RGPCL), compressive bandaging, ${ }^{16,17}$ and surgical treatments such as injection of inert gas $\left(\mathrm{C}_{3} \mathrm{~F}_{8}\right.$ or $\left.\mathrm{SF}_{6}\right)$ into the anterior chamber, corneal cross-linking, epikeratophakia or lamellar keratoplasty. ${ }^{1,18,19}$ However, continued RGPCL wear will damage the corneal epithelium, not well tolerated, and is usually associated with poor long-term efficacy and high recurrence rates in patients with advanced keratoconus. ${ }^{20}$ The severe corneal edema caused by large breaks in DM also limits the likelihood of a complete and successful DALK, which is now the preferred treatment for keratoconus. ${ }^{21}$

We recognized that repairing the break in DM would allow the corneal edema to subside and the corneal stroma to heal, and could create conditions supportive of subsequent lamellar keratoplasty and even DALK. We therefore proposed this novel and effective procedure which combined epikeratophakia with intracameral air injection and DALK using the same corneal graft. Intracameral air injection is an effective therapy that can shorten the period of corneal edema. ${ }^{22}$ In the first-stage surgery, the pathological cornea was covered with an allogenic donor graft and an air bubble was inserted into the anterior chamber to push the detached DM back and adjacent to the stroma. This contributed to rapid closure of the DM wound, after which the severe edema of the recipient graft bed subsided within 1-2 days, as confirmed by the AS-OCT examination. Six months later, the DM repair was strengthened by new collagen deposits secreted by the 
surrounding healthy corneal endothelial cells, ${ }^{23}$ providing a solid structural foundation for the second-stage DALK surgery in the present study, including manual stromal dissection. In the 6 months of follow-up after DALK, AS-OCT examinations showed corneal (stroma plus DM) thickness and BCVA values comparable to those following DALK in keratoconus patients without $\mathrm{ACH} .{ }^{24}$

To our knowledge, this two-step procedure of epikeratophakia with intracameral air injection and DALK has not been reported previously in the medical literature. Currently, sustainable eye banks remain rare in developing countries, and a shortage of donor corneas is the most common problem faced by the corneal surgeon. ${ }^{25}$ The novel procedure we have proposed consists of two keratoplasties, but the same donor graft is used for both procedures, which therefore imposes no additional donor burden and technically avoids the need for a fresh donor cornea for penetrating keratoplasty with associated complications such as endothelial rejection and chronic endothelial dysfunction. ${ }^{26,27}$ In addition, about 2 months after epikeratophakia, the donor graft epithelium had also reepithelized from the limbus of the recipient cornea. Consequently, transplanting the same donor graft in the-second stage DALK surgery also avoided the challenge of regenerating a new corneal epithelial layer, promoting rapid graft healing. ${ }^{28}$

At 2 months after epikeratophakia, 1 eye of 1 patient in this case series showed a complication in the form of a branchshaped neovascularization in the superficial recipient corneal stroma bed. In that patient, all corneal neovascularization was removed after thoroughly dissection during the DALK procedure, and the recipient corneal stroma bed remained transparent during subsequent follow-up.

In conclusion, we propose a novel two-stage procedure for treating $\mathrm{ACH}$, which shows rapid absorption of corneal edema and DM healing and minimizes the risk of postoperative endothelial immune rejection.

\section{Conclusion}

Epikeratophakia followed by DALK using the same corneal graft is an effective operation technology for the treatment of acute corneal hydrops.

\section{Abbreviations}

(DALK): Deep anterior lamellar keratoplasty.

(BCVA): Best-corrected visual acuity.

(AS-OCT): Anterior segment optical coherence tomography.

(ACH): acute corneal hydrops.

(DM): Descemet's membrane.

(RGP): Rigid gas permeable.

(RGPCL): Rigid gas-permeable contact lenses.

\section{Declarations}

Ethics approval: Approval was obtained from the ethics committee of the Shanghai Tongji Hospital, Tongji University School of Medicine. The procedures used in this study adhere to the tenets of the Declaration of Helsinki. 
Consent to participate: Written Informed consent was obtained from all individual participants included in the study.

Consent to publish: Patients signed written informed consent regarding publishing their data and photographs.

Availability of data and material (data transparency): The datasets used and/or analyzed during the current study are available from the corresponding author on reasonable request.

Competing interests: None.

Authors' Contributionsl: All authors contributed to the study conception and design. Material preparation, data collection and analysis were performed by CY Liu, YS Zhang, X Liu and L Zhang. All blepharoplasties were carried out by YL Bi. The first draft of the manuscript was written by CY Liu and JQ Shen and all authors commented on previous versions of the manuscript. All authors read and approved the final manuscript.

Acknowledgements: not applicable.

Funding: This study was supported by the Natural Science Foundation of China (82070920); Shanghai "Science and Technology Innovation Action Plan" Laboratory Animal Research Project (201409006500).

Financial interests/Non-financial interests: The authors have no conflicts of interest to declare that are relevant to the content of this article.

\section{References}

1. Barsam A, Petrushkin H, Brennan N, et al. Acute corneal hydrops in keratoconus: a national prospective study of incidence and management. Eye 2015; 29(4):469-474.

2. McMonnies CW. Mechanisms for acute corneal hydrops and perforation. Eye Contact Lens 2014; 40(4):257-264.

3. Lockington D, Fan Gaskin JC, McGhee CN, et al. A prospective study of acute corneal hydrops by in vivo confocal microscopy in a New Zealand population with keratoconus. Br J Ophthalmol 2014; 98(9):1296-1302.

4. Basu S, Vaddavalli PK, Ramappa M, et al. Intracameral perfluoropropane gas in the treatment of acute corneal hydrops. Ophthalmology 2011;118:934-939.

5. Sharma N, Mannan R, Jhanji V, et al. Ultrasound biomicroscopy-guided assessment of acute corneal hydrops. Ophthalmology 2011;118:2166-2171.

6. Grewal S, Laibson PR, Cohen EJ, et al. Acute hydrops in the corneal ectasias: associated factors and outcomes. Trans Am Ophthalmol Soc 1999; 97:187-203.

7. Aldave AJ, Mabon M, Hollander DA, et al. Spontaneous corneal hydrops and perfora-tion in keratoconus and pellucid marginal degeneration. Cornea 2003; 22:169-174.

8. Alsuhaibani AH, Al-Rajhi AA, Al-Motowa SM, et al. Corneal endothelial cell density and morphology after acute hydrops in keratoconus. Cornea 2008; 27(5):535-538.

9. Fan Gaskin JC, Patel DV, McGhee CN, et al. Acute corneal hydrops in keratoconus - new perspectives. Am J Ophthalmol 2014; 157(5):921-928.

10. Tan JC, Holland SP, Dubord PJ, et al. Evolving indications for and trends in keratoplasty in British Columbia, Canada, from 2002 to 2011: a 10-year review. Cornea 2014; 33(3):252-256.

11. Liu MY, Hong J. Risk Factors for Endothelial Decompensation after Penetrating. J Ophthalmol 2018; 2018:1389486.

12. Li J, Yu L, Deng Z, et al. Deep anterior lamellar keratoplasty using acellular corneal tissue for prevention of allograft rejection in high-risk corneas. Am J Ophthalmol 2011; 152(5):762-770. 
13. Davidson AE, Hayes S, Hardcastle AJ, et al. The pathogenesis of keratoconus. Eye 2014; 28(2):189-195.

14. Carter JB, Jones DB, Wilhelmus KR. Acute hydrops in pellucid marginal corneal degeneration. Am J Ophthalmol 1989; 107(2):167-170.

15. Tuft SJ, Gregory WM, Buckley RJ. Acute corneal hydrops in keratoconus. Ophthalmology 1994; 101(10):17381744.

16. Dogan C, Hagverdiyeva S, Mergen B, et al. Effect of the rigid gas-permeable contact lens use on the endothelial cells in patients with keratoconus. Eye Contact Lens 2018; 44 Suppl 2:S314-S317.

17. Downie LE, Lindsay RG. Contact lens management of keratoconus. Clin Exp Optom 2015; 98(4):299-311.

18. Campos Polo R, Chacón Iglesias J, Gamazo Carrasco M, et al. Management of corneal hydrops using air and micropunctures. Arch Soc Esp Oftalmol 2015; 90(4): 198-201.

19. Palioura S, Chodosh J, Pineda R. A novel approach to the management of a progressive Descemet membrane tear in a patient with keratoglobus and acute hydrops. Cornea 2013; 32(3):355-358.

20. Parker JS, van Dijk K, Melles GR. Treatment options for advanced keratoconus: A review. Surv Ophthalmol 2015; 60(5):459-480.

21. Li S, Liu M, Wang Q, et al. Lamellar keratoplasty following thermokeratoplasty in the treatment of acute corneal hydrops. Am J Ophthalmol 2014; 158(1):26-31.

22. Miyata K, Tsuji H, Tanabe T, et al. Intracameral air injection for acute hydrops in keratoconus. Am J Ophthalmol 2002; 133(6):750-752.

23. Lin W, Zhu YR, Chen W. Ultrastructure of the Interface between Descemet's Membrane and the Posterior Stroma. Chin J Optom Ophthalmol Vis Sci 2019; 21(2): 97-103.

24. Romano V, lovieno A, Parente G, et al. Long-term clinical outcomes of deep anterior lamellar keratoplasty in patients with keratoconus. Am J Ophthalmol 2015; 159(3):505-511.

25. Pineda R. Corneal transplantation in the developing world: Lessons learned and meeting the challenge. Cornea 2015; 34 Suppl 10:S35-S40.

26. Chen JY, Jones MN, Srinivasan S, et al. Endophthalmitis after penetrating keratoplasty. Ophthalmology 2015;122(1):25-30.

27. Kharod-Dholakia B, Randleman JB, Bromley JG, et al. Prevention and treatment of corneal graft rejection: current practice patterns of the Cornea Society (2011). Cornea 2015; 34(6):609-614.

28. Tan DT, Dart JK, Holland EJ, et al. Corneal transplantation. Lancet 2012; 379(9827):1749-1761.

\section{Figures}




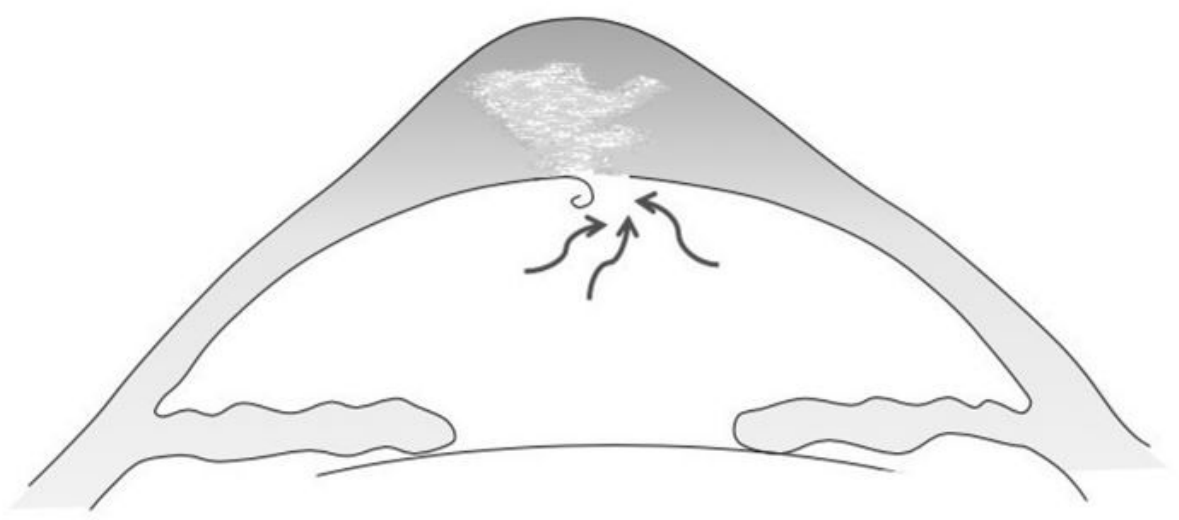

$\mathbf{A}$

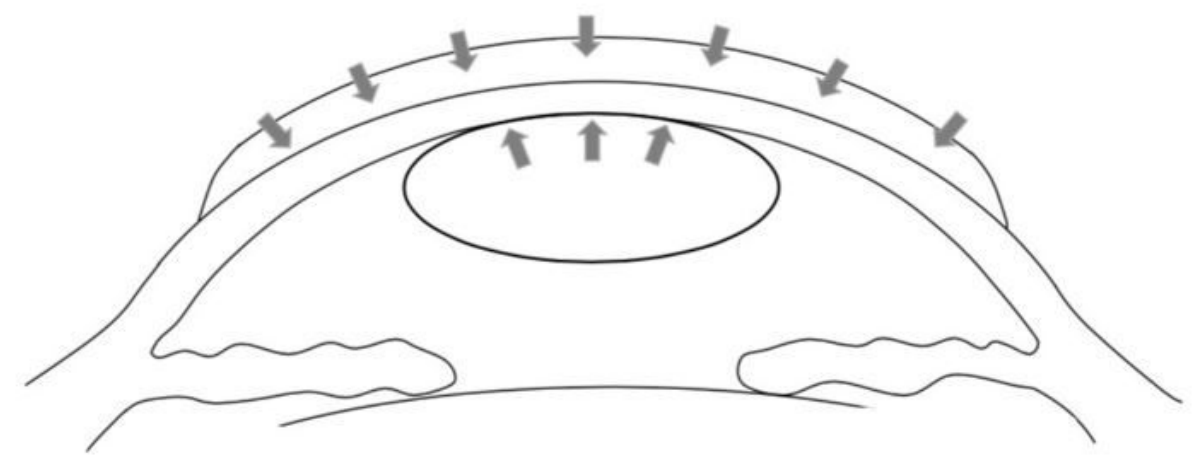

B

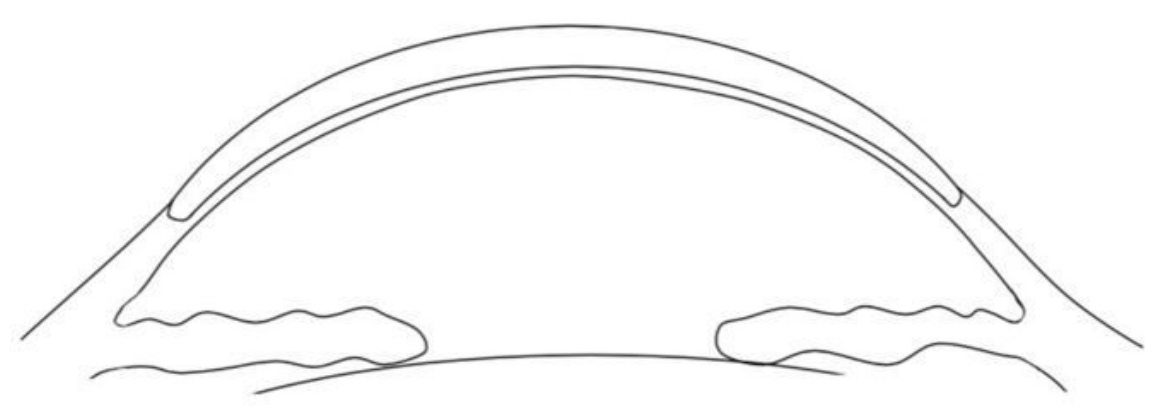

C

Figure 1

Schematic drawing of the two-stage one-graft method. A, Acute corneal hydrops in advanced keratoconus due to rupture of Descemet's membrane and subsequent intrastromal fluid accumulation. B, First-stage surgery. The pathological cornea was covered and pressed with an allogenic donor graft and the detached DM was pushed upward by an injected sterile air bubble. The disrupted DM was allowed to reset and heal, and the severe edema subsided rapidly. C, Approximately 6 months later, the second-stage DALK was performed using the same donor graft. 


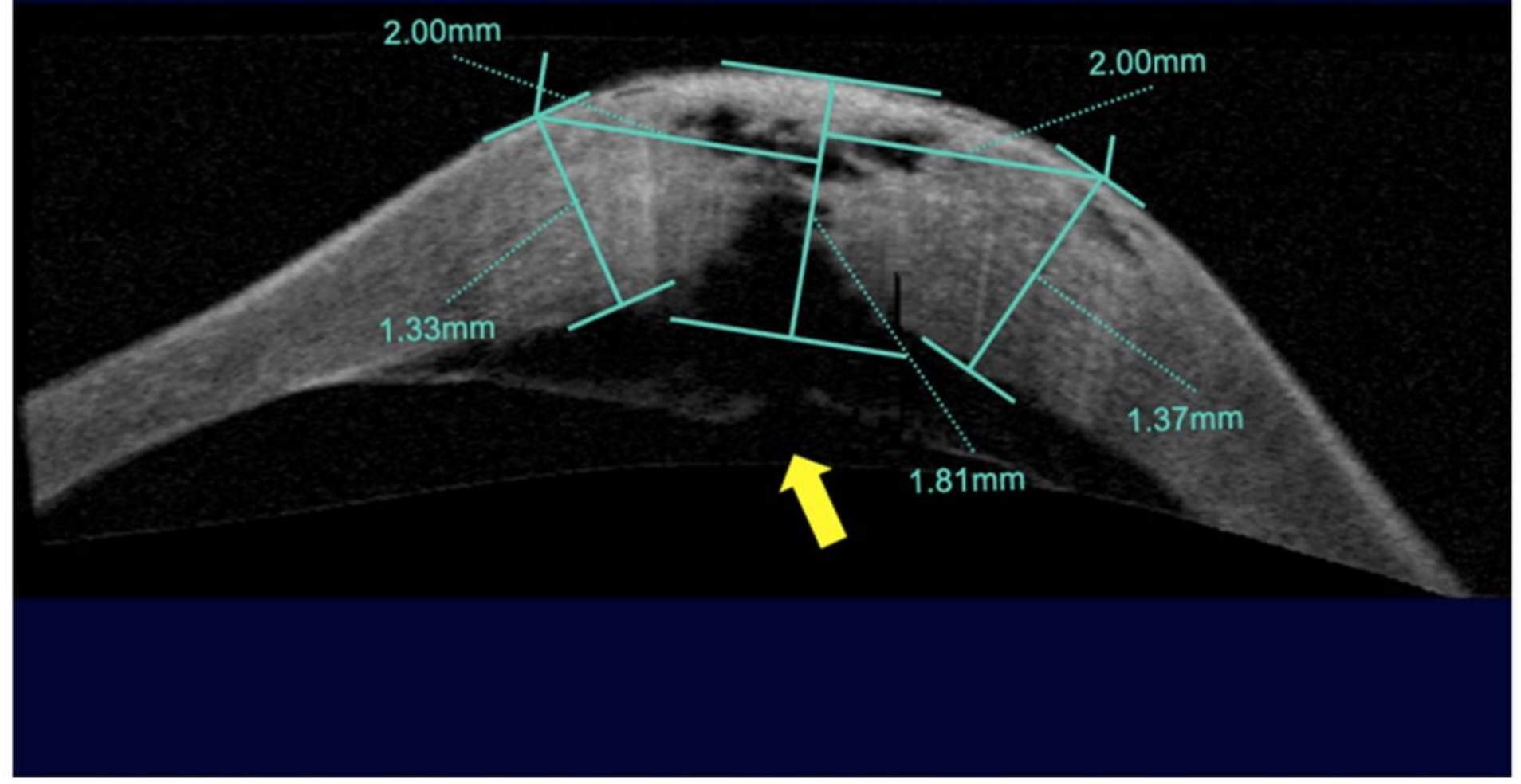

\section{Figure 2}

Measurement of corneal thickness using anterior segment optical coherence tomography (AS-OCT) after acute corneal hydrops. Indicated from left to right are the corneal thickness $2 \mathrm{~mm}$ nasal to the corneal apex with a horizontal scan, the corneal thickness at the apex, and the corneal thickness $2 \mathrm{~mm}$ temporal to the corneal apex with a horizontal scan. The yellow arrow indicates a break in Descemet's membrane. 

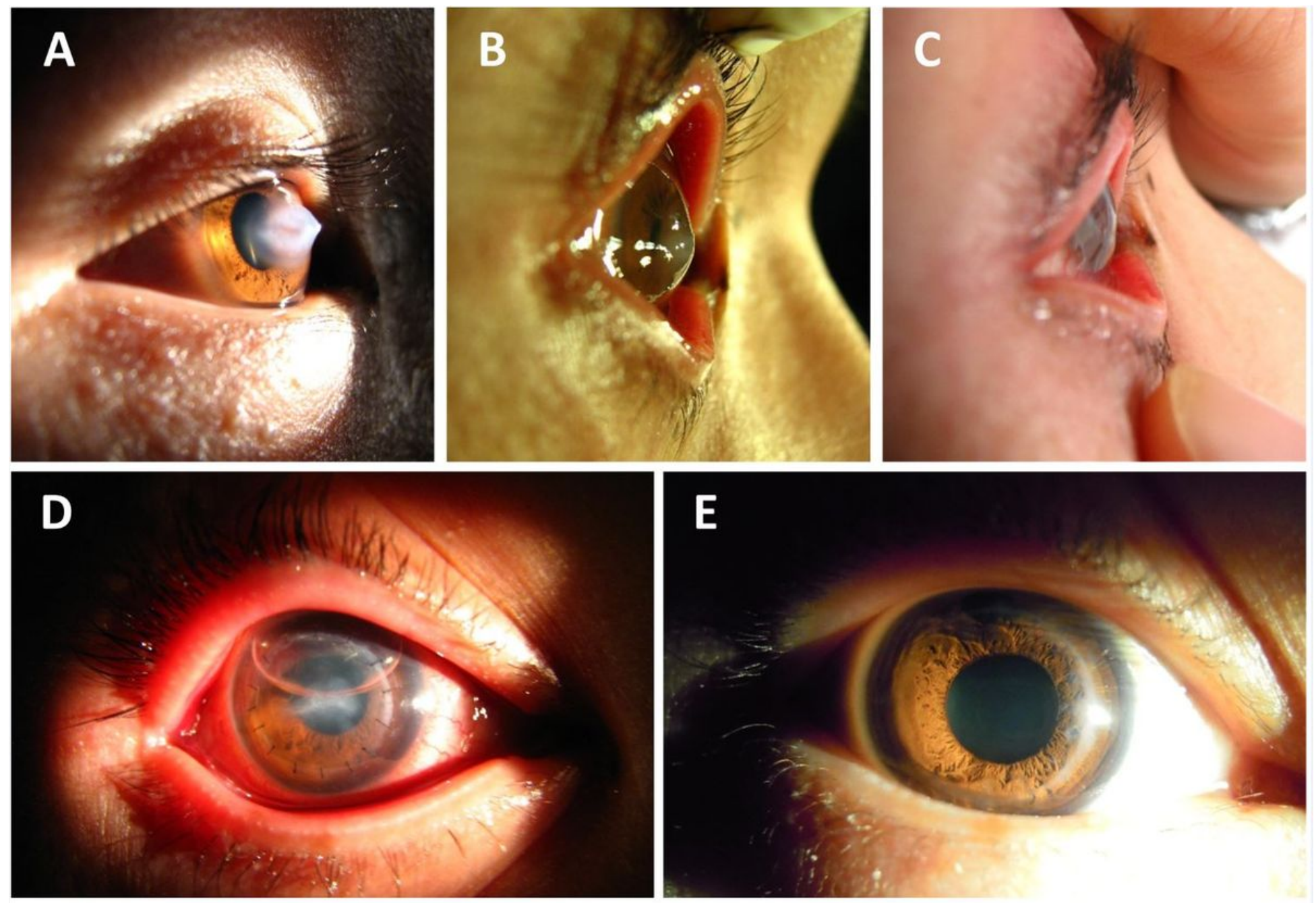

\section{Figure 3}

A patient with $\mathrm{ACH}$ treated with the epikeratophakia-DALK combination after a first treatment with thermokeratoplasty. A, Acute onset $\mathrm{ACH}$, with severe edema of the corneal stroma. $\mathrm{B}, \mathrm{At} 2$ weeks after thermokeratoplasty a recurrence of edema was evident centrally, and epikeratophakia was performed immediately. C and D, At 2 days after epikeratophakia, the corneal haze and edema had noticeably subsided. E, At 3 months after DALK using the same graft, the cornea was transparent.
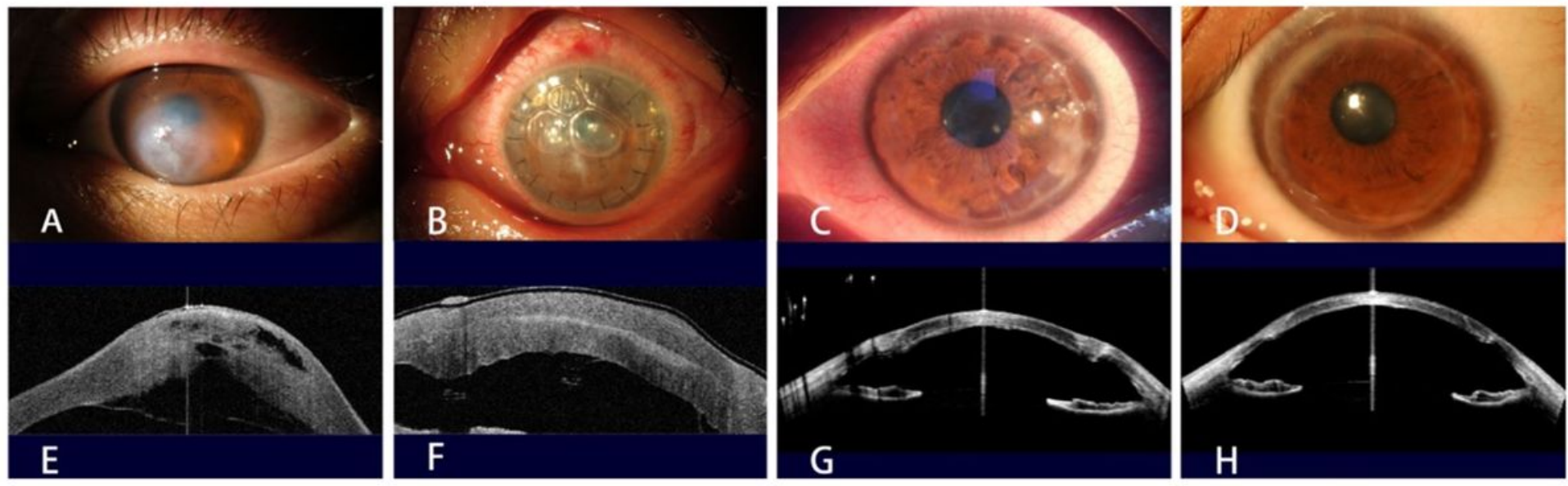

Figure 4 
Slit-lamp photographs and anterior segment optical coherence tomography (AS-OCT) scans show the evolution of a patient with $\mathrm{ACH}$ treated using the novel techniques. $\mathrm{A}$ and $\mathrm{E}$, Acute onset $\mathrm{ACH}$, with severe edema of the corneal stroma evident under slit-lamp examination and with a DM break and detachment observed by AS-OCT. B and F, One day after the first-stage surgery, at presentation, with double layers of cornea observed on slit-lamp and AS-OCT examinations, with no corneal edema and with DM attached. C and G, One week after the second-stage surgery, the corneal graft, which was the same graft used in the first-stage operation, had survived and attached to the host's residual stroma bed with a healed DM and corneal endothelial. $\mathrm{D}$ and $\mathrm{H}$, One year after the second stage surgery, the cornea was transparent and the logMAR BCVA was 0.096. 